\title{
Thermoelectric Cooling Block
}

\author{
Evgenii N. Vasil'ev*a, \\ Ehl'mar R. Gejnts', Valeriy A. Derevyanko ${ }^{\mathrm{a}}$, \\ Evgenii G. Kokov ${ }^{b}$ and Sergei V. Kukushkin ${ }^{\mathrm{a}}$ \\ ${ }^{a}$ Institute of Computational Modelling SB RAS \\ 50/44 Akademgorodok, Krasnoyarsk, 660036, Russia \\ ${ }^{b}$ RPC "Poljus" JSC \\ 56v Kirov, Tomsk, 634050, Russia
}

Received 27.12.2018, received in revised form 25.01.2019, accepted 01.02.2019

Theoretical and experimental studies of heat exchange processes in the thermoelectric block of a refrigeration unit designed for ship freezers and provision chambers have been carried out. In the original design of the block, which includes 8 thermoelectric modules S-199-1411, thermosyphons, a liquid heat exchanger with counter coolant flows and vacuuming volume were used to accommodate thermoelectric modules, which allowed minimizing heat losses and increasing cooling efficiency. Using a mathematical model, the performance characteristics and modes of operation of the refrigeration unit under different conditions and layout options are calculated. An experimental model of a thermoelectric unit was created and tested, the values of cooling power in various operating modes were determined.

Keywords: thermoelectric module, refrigeration unit, thermosiphon, heat exchange, thermal conductivity, radiator.

Citation: Vasil'ev E.N., Gejnts E.R., Derevyanko V.A., Kokov E.G., Kukushkin S.V. Thermoelectric cooling block, J. Sib. Fed. Univ. Eng. technol., 2019, 12(2), 146-152. DOI: 10.17516/1999-494X-0123.

(c) Siberian Federal University. All rights reserved

This work is licensed under a Creative Commons Attribution-NonCommercial 4.0 International License (CC BY-NC 4.0).

* Corresponding author E-mail address: ven@icm.krasn.ru 


\title{
Термоэлектрический блок охлаждения
}

\author{
Е.Н. Васильев ${ }^{a}$, Э.Р. Гейнц \\ В.А. Деревянко ${ }^{\mathrm{a}}$ Е.Г. Коков ${ }^{\sigma}$, С.В. Кукушкин ${ }^{\mathrm{a}}$ \\ ${ }^{a}$ Институт вычислительного моделирования СО РАН \\ Россия, 660036, Красноярск, Академгородок, 50/44 \\ ${ }^{6}$ АО НПЦ «Полюс» \\ Россия, 634050, Томск, пр. Кирова, 568
}

Проведень теоретические и экспериментальные исследования прочессов теплообмена 6 термоэлектрическом блоке холодильной установки, предназначенной для судовых морозильных и провизионных камер. В оригинальной конструкции блока, включающей в себя 8 термоэлектрических модулей S-199-14-11, применены термосифоны, жидкостной теплообменник со встречными потоками охлаждающей жидкости и вакуумирование объема для размещения термоэлектрических модулей, что позволило до минимума снизить тепловые потери и повысить эффективность охлаждения. С помощью математической модели рассчитаны рабочие характеристики и режимы работы блока холодильной установки при различных условиях и вариантах компоновки. Создан экспериментальный образеи термоэлектрического блока, и проведены его испытания, определены значения холодильной мощьности в различных режимах работы.

Ключевые слова: термоэлектрический модуль, холодильная установка, термосифон, теплообмен, теплопроводность, радиатор.

\section{Введение}

В настоящее время термоэлектрические модули (ТЭМ) широко используются для охлаждения как микрообъектов (микросхемы, транзисторы и пр.), так и холодильных камер большого объема $[1,2]$. Достоинствами термоэлектрических холодильных установок (ТЭХУ) являются компактность, надежность, экологичность и бесшумность, основным недостатком - сравнительно низкая эффективность охлаждения. Одним из путей повышения эффективности ТЭХУ служит оптимизация конструкции, позволяющая снизить температурные перепады на термических сопротивлениях на элементах конструкции и максимально использовать потенциал существующих ТЭМ. Важной характеристикой ТЭХУ также признано удобство эксплуатации и обслуживания. В настоящей работе представлена оригинальная конструкция, а также результаты вычислительного моделирования и испытаний экспериментального образца термоэлектрического блока охлаждения для судовых морозильных и провизионных камер. В конструкции этого блока использованы современные технические решения, обеспечивающие значительное повышение эффективности как системы теплоподвода, так и всей ТЭХУ в целом.

\section{Описание конструкции ТЭХУ}

При разработке конструкции ТЭХУ был взят за основу блочно-модульный принцип компоновки. Конструктивно блок ТЭХУ является независимым модулем, расположенным за пределами судовой камеры для хранения продуктов. Камера и блок ТЭХУ связаны между собой посредством двух воздуховодов: по одному из них вентилятором нагнетается «холодный» воздух из агрегатного блока в продуктовую камеру, по другому возвращается «теплый» воз- 
дух. Эта компоновка холодильной установки обеспечивает как более высокие эксплуатационные качества, так и удобство обслуживания. В объеме судовой камеры отсутствует теплообменник, и охлаждение продуктов производится холодным воздухом, поступающим из агрегатного блока. Этот принцип работы, называемый “no frost", в настоящее время используется и в современных бытовых компрессорных холодильниках. Такой способ охлаждения устраняет причину намерзания льда в камере и обеспечивает ее длительную работу без снижения эффективности, не требуя профилактического размораживания камеры. Замена агрегатного блока для ремонта или профилактического обслуживания может быть осуществлена быстро, для этого нет необходимости проводить работы в объеме холодильной камеры и извлекать из нее продукты, нужно только отсоединить воздуховоды и заменить агрегатные блоки. Иней с ребер воздушного радиатора периодически удаляется путем включения встроенного электрического нагревателя, при этом вентилятор отключается, а воздуховоды перекрываются.

При разработке блока ТЭХУ особое внимание было обращено на вопросы оптимизации теплообмена и выбора режимов работы с целью повышения эффективности работы и увеличения холодопроизводительности, а также возможности поддержания захоложенного состояния в холодильной камере при отключенном электропитании. На основе анализа процесса теплообмена и рабочих характеристик ТЭМ разработана конструкция блока ТЭХУ (рис. 1), в которой применены технические решения, позволяющие решить поставленные вопросы [3]. Повышение эффективности работы ТЭХУ обеспечивается за счет следующих технических решений:

1) размещение ТЭМ в вакуумированном объеме, что исключает потери, обусловленные конвективным теплопереносом и конденсацией влаги;

2) использование термосифонов, препятствующих обратным теплоперетокам и обеспечивающих эффективную теплопередачу от воздушного радиатора к холодному спаю секции ТЭМ, что снижает до минимума потери перепада температуры, созданного ТЭМ;

3) охлаждение горячих спаев ТЭМ жидкостным теплообменником со встречными потоками охлаждающей жидкости, обеспечивающим равномерность температурного поля и эффективно отводящим теплоту во внешнюю среду.

В термосифонах теплопередача за счет движения и фазовых превращений теплоносителя возможна только в одном направлении: от воздушного радиатора к холодным спаям ТЭМ. В обратном направлении теплопередача может происходить только по стенкам; для минимизации этих потерь термосифоны изготавливались тонкостенными (0,5 мм) из металла с низким коэффициентом теплопроводности (нержавеющая сталь). Это позволило предотвратить обратные перетоки теплоты из внешней среды в объем продуктовой камеры через ТЭХУ при отключении электропитания.

В состав разработанного блока ТЭХУ входят: секция из 8 ТЭМ типа S-199-14-11 производства НПО «Кристалл», 24 термосифона, воздушный «холодный» радиатор, жидкостной «горячий» радиатор, электродвигатель с вентилятором. Количество блоков ТЭХУ, устанавливаемых в продуктовых камерах, зависит от их назначения и объема. Функционирование блока ТЭХУ предполагается в двух основных режимах: поддержание значений температуры $3{ }^{\circ} \mathrm{C}$ в провизионной камере и минус $18{ }^{\circ} \mathrm{C}$ в морозильной камере. 


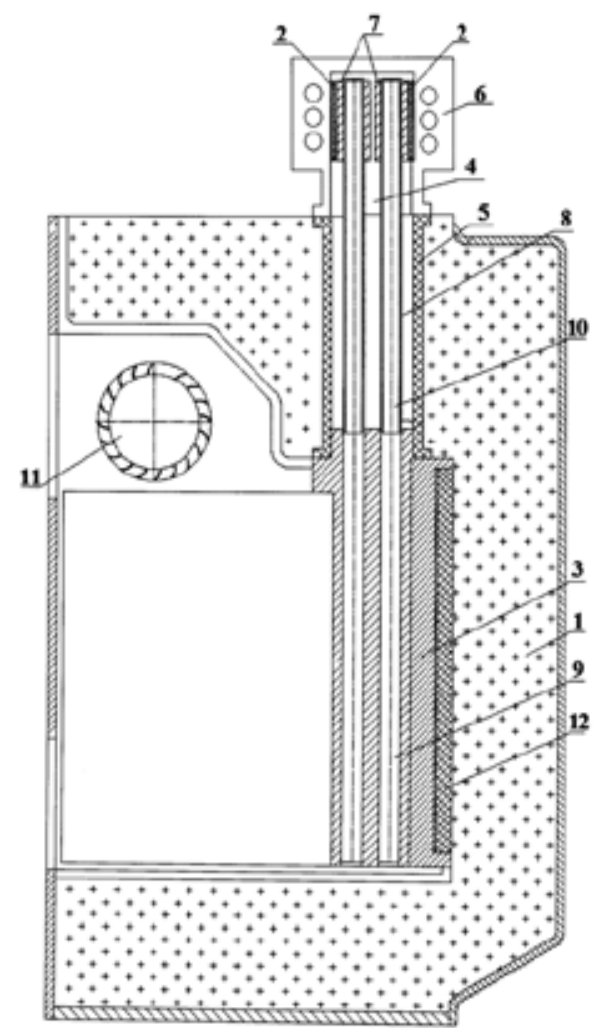

Рис. 1. Конструкция блока ТЭХУ: 1 - теплоизолированный корпус; 2 - ТЭМ; 3 - воздушный радиатор; 4 - герметичная камера; 5 - теплоизолирующая вставка; 6 - жидкостной радиатор; 7 - конденсатор термосифона; 8 - корпус термосифона; 9 - зона испарения термосифонов; 10 - внутренний паропровод термосифона; 11 - вентилятор; 12 - электрический нагреватель

Fig. 1. The design of block of thermoelectric refrigeration unit: 1 - heat insulated casing; 2 - thermoelectric modules; 3 - air radiator; 4 - sealed chamber; 5 - heat insulating insert; 6 - liquid radiator; 7 - thermosyphon condenser; 8 - thermosyphon case; 9 - evaporation zone of thermosyphons; 10 - the inner steam pipe of thermosyphon; 11 - fan; 12 - electric heater

\section{Определение рабочих характеристик ТЭХУ}

Для расчета рабочих характеристик и оптимизации конструкции блока ТЭХУ была разработана математическая модель, описывающая процесс теплопередачи во всех элементах блока ТЭХУ. Модель включает в себя расчетные алгоритмы, позволяющие рассчитывать характеристики как отдельных узлов, так и всего блока ТЭХУ в целом [4-8]. Расчет характеристик воздушного и жидкостного радиаторов проводился на основе решения уравнения теплопроводности, из которого определялось распределение температуры по высоте ребер с учетом размеров и материала ребер, значения локального коэффициента теплообмена для заданной скорости воздуха или жидкости. При этом рассчитывали коэффициент теплообмена воздушного радиатора, расход воздуха и перепад давления на воздушном радиаторе, коэффициент теплообмена жидкостного радиатора, изменение температуры охлаждающей жидкости при прохождении по жидкостному радиатору. В итоге математическая модель позволяет определить холодопроизводительность блока ТЭХУ при различных условиях работы и вариантах компоновки. 
Для натурных исследований рабочих характеристик блока ТЭХУ был изготовлен экспериментальный образец (рис. 2) и собран испытательный стенд, на котором регистрацию и обработку параметров работы обеспечивает автоматизированный вычислительный комплекс на базе модульной измерительной системы L-Card и персонального компьютера с использованием «Пакета прикладных программ для регистрации и обработки результатов тепловых и электрических параметров». В ходе проведенных испытаний экспериментального образца получены значения холодильной мощности $Q$ блока ТЭХУ для морозильной (температура минус $18{ }^{\circ} \mathrm{C}$ ) и провизионной (температура $3{ }^{\circ} \mathrm{C}$ ) камер при значениях температуры охлаждающей жидкости $T_{0}=9{ }^{\circ} \mathrm{C}$ и $20^{\circ} \mathrm{C}$.

Рассчитанные зависимости холодильной мощности $Q$ от температуры охлаждающей жидкости приведены на рис. 3 для режимов работы блока ТЭХУ, соответствующих морозильной (сплошная линия) и провизионной (пунктирная линия) камерам. С увеличением температуры охлаждающей жидкости величина $Q$ снижается по линейному закону. Здесь же отмечены значения $Q$, полученные в ходе испытаний блока ТЭХУ, квадратики соответствуют режиму морозильной камеры, кружки относятся к режиму провизионной камеры. Собственная потребляемая электрическая мощность блока ТЭХУ в этих режимах составила примерно 800 Вт.

\section{Заключение}

Проведенные испытания экспериментального образца подтвердили эффективность конструктивных и технических решений, примененных в блоке ТЭХУ. По результатам испытаний сделаны следующие выводы.

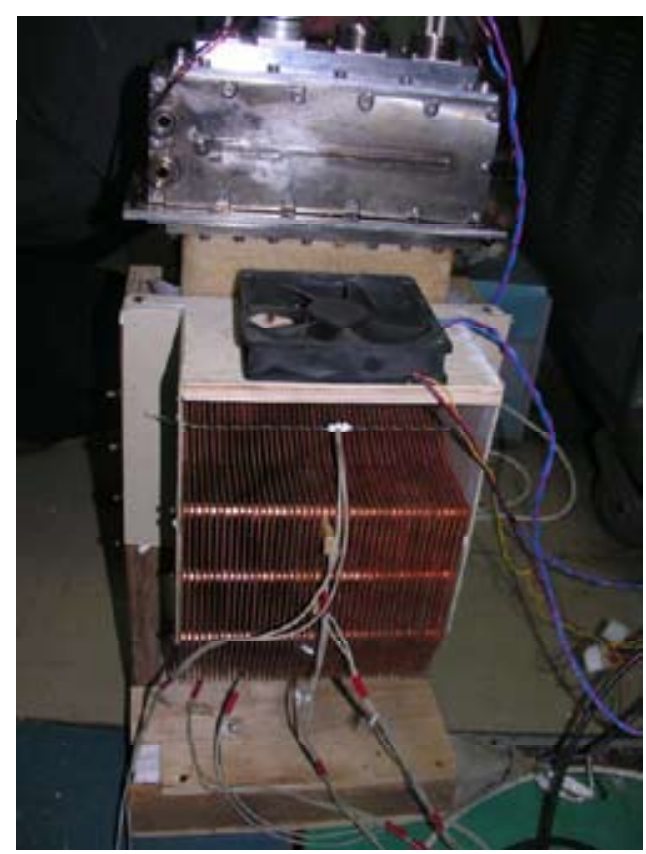

Рис. 2. Экспериментальный образец блока ТЭХУ

Fig. 2. Experimental sample of block of thermoelectric refrigeration unit 


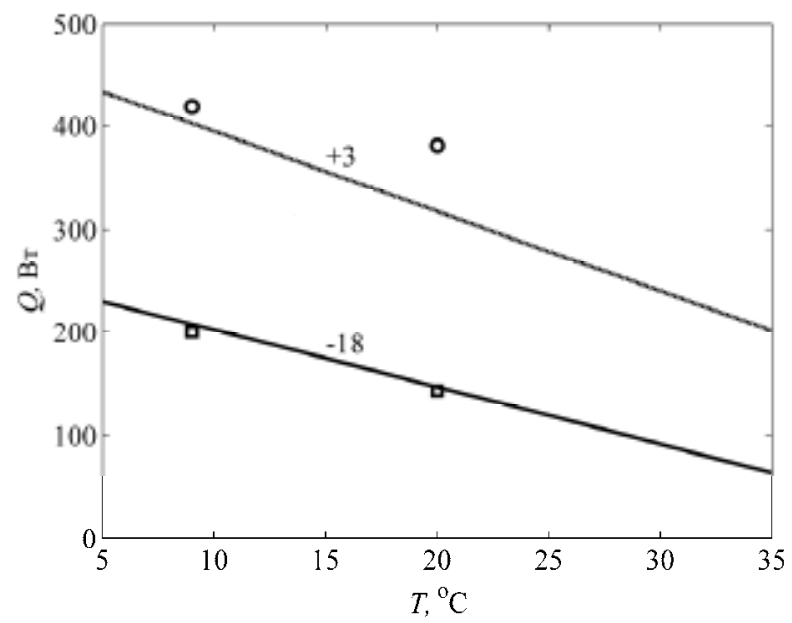

Рис. 3. Зависимости холодильной мощности $Q$ от температуры охлаждающей жидкости для морозильной (температура минус $18^{\circ} \mathrm{C}$ ) и провизионной (температура $3^{\circ} \mathrm{C}$ ) камер

Fig. 3. Dependencies of cooling capacity $Q$ on coolant temperature for freezing $\left(-18^{\circ} \mathrm{C}\right.$ temperature $)$ and provisioning $\left(+3{ }^{\circ} \mathrm{C}\right.$ temperature $)$ chambers

1. Применение вакуумной теплоизоляции ТЭМ исключило негативное влияние конвекции и теплопроводности воздуха и конденсации влаги, что позволило приблизить рабочие характеристики к предельно достижимым.

2. Термосифоны обеспечивают эффективную теплопередачу от воздушного радиатора к холодному спаю ТЭМ и выполняют функцию тепловых затворов между воздушным радиатором и ТЭМ, что позволяет устранить проникновение теплоты из внешней среды в холодильную камеру при отключении питания или выходе ТЭМ из строя. Кроме того, наличие теплового затвора дает возможность производить регулирование температуры в холодильной камере не только путем изменения силы тока, но и традиционным для бытовых холодильников способом с применением термореле для периодического отключения питания.

3. Размещение воздушного радиатора блока ТЭХУ за пределами холодильной камеры позволило использовать принцип работы “no frost” и повысить удобство в эксплуатации и обслуживании.

По результатам исследований определены пути и возможности доработки конструкции блока ТЭХУ при создании опытного образца.

\section{Список литературы}

[1] Анатычук Л.И., Вихор Л.Н., Николаенко Ю.Е., Рассамакин Б.М., Розвер Ю.Ю. Крупноформатный термоэлектрический модуль охлаждения с тепловыми трубами. Термоэлектричество, 2011, (1), 53-59 [Anatychuk L.I., Vichor L.N., Nikolaenko Yu.Ye. Rassamakin B.M., Rozver Yu.Yu. Large-sized thermoelectric module with heat pipes. Journal of Thermoelectricity, 2011, (3), 60-75]

[2] Санин В.Н., Андреков И.К., Цапаев А.П., Копылова Н.А. Термоэлектрическое охлаждение радиоэлектронной аппаратуры, Известия ВУЗов. Радиоэлектроника, 2003, (9), 60-65 
[Sanin V.N., Andrekov I.K., Tsapaev A.P., Kopylova N.A. Thermoelectric cooling of electronic devices. Radioelectronics and communications systems, 2003, (9), 60-65]

[3] Патент 2511922 (РФ) от 10.04.14 г, МПК F25B 21/02. Термоэлектрический блок охлаждения / Деревянко В.А., Гладущенко В.Н., Гейнц Э.Р., Коков Е.Г., Васильев Е.Н., Руссков В.В. [Patent 2511922 (RF), dated 10.04.14, MPK F25B 21/02. Thermoelectric cooling unit / Derevjanko V.A., Gladushchenko V.N., Gejnts E.R., Kokov E.G., Vasil'ev E.N.,Russkov V.V. (in Russian)]

[4] Васильев Е. Н., Деревянко В. А. Анализ эффективности применения термоэлектрических модулей в системах охлаждения радиоэлементов. Вестник СибГАУ, 2013, (4), 9-13 [Vasil'ev E.N., Derevyanko V.A. Analysis of thermoelectric modules efficiency in cooling systems. Vestnik SibGAU, 2013, (4), 9-13 (In Russian)]

[5] Васильев Е. Н. Математическая модель для расчета характеристик термоэлектрических модулей охлаждения. Журнал СФУ. Техника и технология, 2015, 8(8), 1017-1023 [Vasil'ev E.N. Mathematical Model for the Calculation of the Characteristics of the Cooling Thermoelectric Modules. J. Sib. Fed. Univ. Eng. technol. 2015, 8(8), 1017-1023 (In Russian)]

[6] Васильев Е.Н. Расчет и оптимизация режимов термоэлектрического охлаждения теплонагруженных элементов. Журнал технической физики, 2017, 62(1), 90-96 [Vasil'ev E.N. Calculation and Optimization of Thermoelectric Cooling Modes of Thermally Loaded Elements. Technical Physics, 2017, 62(1), 90-96]

[7] Васильев Е.Н. Оптимизация режимов термоэлектрического охлаждения теплонагруженных элементов с учетом термического сопротивления теплоотводящей системы. Журнал технической физики, 2017, 62(9), 1300-1306 [Vasil'ev E.N. Optimization of Thermoelectric Cooling Regimes for Heat-Loaded Elements Taking into Account the Thermal Resistance of the Heat-Spreading System. Technical Physics, 2017, 62(9), 1300-1306]

[8] Васильев Е.Н. Расчет термического сопротивления теплораспределителя системы охлаждения теплонагруженного элемента. Журнал технической физики, 2018, 63(4), 471-475 [Vasil'ev E. N. Calculation of the Thermal Resistance of a Heat Distributer in the Cooling System of a Heat-Loaded Element. Technical Physics, 2018, 63(4), 471-475] 